\title{
ANALISIS KEGAGALAN KONSTRUKSI DARI PERSPEKTIF SOCIO - ENGINEERING SYSTEM
}

\author{
Riki Saputra ${ }^{1}$, Akhmad Suraji ${ }^{2}$, Abdul Hakam ${ }^{3}$
}

\begin{abstract}
ABSTRAK
Salah satu penyebab utama kerentanan fisik dan lingkungan adalah kegiatan manusia dalam membangun lingkungan-binaannya, dan hal ini sangat erat terkait dengan sektor konstruksi. Cara membangun yang salah, baik dari segi perencanaan dan perancangan maupun dari segi pelaksanaan dan pengawasannya dapat menghasilkan infrastruktur yang rentan terhadap bencana, selain juga risiko degradasi lingkungan. Hasil studi data statistik kegagalan, memperlihatkan bahwa Practitioners mempunyai saham dan potensi yang lebih besar dari Theoreticians dalam menekan resiko kegagalan. Persentasi resiko terbesar datang dari Human Activities dan Human Attitude. Socio-Engineering berfokus pada atribut yang melekat pada seseorang seperti , sikap (attitude), keahlian (skill), nilai/norma yang diyakini (values), relasi sesama manusia, pengakuan dan penghargaan (reward system), wewenang struktural (authority structure). Hasil penelitian ini dapat dijadikan suatu teori yang berfungsi untuk menjelaskan, meramalkan, dan mengontrol suatu gejala. Penelitian ini menganalisis Kegagalan Konstruksi dari Perspektif Socio - Engineering System. Pengaruh Socio - Engineering System terhadap kegagalan kontruksi dan bangunan sangat beresiko ( 66,7 \%) dalam artinya perilaku manusia memiliki peranan yang cukup berarti dalam kegagalan konstruksi. Kegagalan konstruksi dilihat dari perspektif socio engineering system yang berpengaruh yaitu pada tahap perencanaan, dokumen perencanaan dan proses pengadaan. Pada tahap ini faktor yang dapat mengakibatkan kegagalan kontruksi, seperti persaingan yang tidak sehat ,korupsi, kolusi, nepotisme, (KKN) dan penyuapan agar memenangkan tender Pengadaan Barang dan Jasa $(90,00 \%)$, Terjadinya persekongkolan dengan Owner untuk mengatur harga penawaran diluar prosedur pengadaan $(80,00 \%)$, Keinginan Owner untuk meraih keuntungan yang tidak normal ( Fee Proyek ) dengan menekan imbalan jasa dari konsultan Perencana / Kontraktor diluar kontrak yang telah disepakati $(76,7 \%)$.
\end{abstract}

Kata Kunci : Analisis kegagalan konstruksi, socio - engineering system, resiko, sikap, prilaku

\section{PENDAhuluan}

Salah satu penyebab utama kerentanan fisik dan lingkungan adalah kegiatan manusia dalam membangun lingkungan-binaannya, dan hal ini sangat erat terkait dengan sektor konstruksi. Cara membangun yang salah, baik dari segi perencanaan dan perancangan maupun dari segi

\footnotetext{
${ }^{1}$ Mahasiswa Pascasarjana Jurusan Teknik Sipil Fakultas Teknik Universitas Andalas, rikisaputra002@gmail.com

${ }^{2}$ Staf Pengajar Jurusan Teknik Sipil Fakultas Teknik Universitas Andalas, akhmad.suraji@gmail.com

${ }^{3}$ Staf Pengajar Jurusan Teknik Sipil Fakultas Teknik Universitas Andalas, ahakam2008@yahoo.com
} 
pelaksanaan dan pengawasannya dapat menghasilkan infrastruktur yang rentan terhadap bencana, selain juga risiko degradasi lingkungan.

Untuk mendapatkan faktor penyebab kegagalan konstruksi tidaklah mudah. Seringkali sumber dari kegagalan itu sendiri merupakan akumulasi dari berbagai faktor. Oyfer (2002) menyatakan bahwa "Construction failures, including quality defects may stem from not only single but also multiple sources”. Sedangkan Pranoto (2007) menyebutkan bahwa sumber kegagalan konstruksi seringkali dipengaruhi oleh faktor alam dan perilaku manusia. Faktor alam dicontohkan sebagai kegagalan yang terjadi akibat perubahan dinamik dari alam seperti letusan gunung berapi, banjir, gelombang laut dan gempa bumi. Perilaku manusia juga berperan signifikan terhadap kegagalan konstruksi. Vickynason (2003) menyatakan bahwa $80 \%$ dari total projects risk in construction dimungkinkan penyebabnya faktor manusia. Riset yang dilakukan Oyfer (2002) menyatakan "construction defects" di Amerika disebabkan oleh faktor manusia (54\%), desain (17\%), perawatan (15\%), material (12\%), dan hal tak terduga (2\%).

Pada umumnya kasus pada pekerjaan konstruksi didominasi oleh penyimpangan berupa pengaturan lelang, kekurangan volume pekerjaan, ketidak-sesuaian spesifikasi berupa pengurangan kualitas pekerjaan, pemahalan harga atau mark up dan keterlambatan penyelesaian pekerjaan. Hal ini merupakan penyimpangan pada pekerjaan konstruksi. Yang nantinya hal ini akan menimbulkan gejala lain, yang tampaknya meningkat menjadi lebih dominan pada masa resesi ekonomi dewasa ini. Gejala dimulai dari keinginan dari pihak yang terkait memperoleh short-term profit dengan menempuh jalur yang tidak normal dan menggantinya dengan kompetisi yang didasarkan pada besarnya angka rupiah semata.

Dengan memahami hal tersebut, dapat dikembangkan kebijakan-kebijakan pro-aktif untuk membangun konstruksi Indonesia agar mampu berperan positif dalam mengurangi risiko kegagalan konstruksi

\section{LANDASAN TEORI}

\subsection{Kegagalan Konstruksi}

Undang - Undang $18 / 1999$ tentang Jasa Konstruksi pasal 22 ayat $\mathrm{g}$ mengamanatkan bahwa ketentuan tentang tanggung jawab dalam hal salah satu pihak tidak melaksanakan kewajiban sebagaimana diperjanjikan harus dituangkan dalam kontrak kerja konstruksi, sedangkan dalam Peraturan Pemerintah Nomor: 29 Tahun 2000 tentang Penyelenggaraan Jasa Konstruksi pasal 31 menyatakan bahwa yang dimaksud dengan kegagalan konstruksi adalah keadaan hasil pekerjaan konstruksi yang tidak sesuai dengan spesifikasi pekerjaan sebagaimana disepakati dalam kontrak kerja konstruksi baik sebagian maupun keseluruhan sebagai akibat dari kesalahan dari pengguna jasa atau penyedia jasa. Kegagalan konstruksi merupakan kegagalan yang bersifat teknis dan non teknis. Kegagalan ini dapat disebabkan karena kegagalan pada proses pengadaan barang/jasa, atau kegagalan saat proses pelaksanaan konstruksi.

\subsection{Socio-Engineering}

Socio-Engineering adalah bidang kajian ilmu yang menggabungkan antara system sosial (people and society) dan system rekayasa kedalam satu sistem- socio engineering. Social system berfokus pada atribut yang melekat pada seseorang seperti, sikap (attitude), keahlian(skill), nilai/norma yang diyakini (values), relasi sesama manusia, pengakuan dan penghargaan (reward system), wewenang struktural (authority structure). Engineering System berfokus pada process, task, sumber daya, kegiatan, yang digunakan untuk mentransformasi dari input menjadi output

\subsection{Hubungan Kerja Pemangku Kepentingan}

\section{0 | JURNAL REKAYASA SIPIL}


Usaha untuk mewujudkan proyek diawali dari tahap ide/gagasan hingga tahap pelaksanaan bahkan hingga masa operasional dan pemeliharaan.Pemangku kepentingan yang terlibat dalam proyek konstruksi dari tahap perencanaan sampai tahap pelaksanaan dapat dikelompokan menjadi tiga pihak, yaitu pihak pemilik proyek (Owner) atau principal (employer/client/bouwheer), pihak perencana (designer) dan pihak Penyedia Jasa Pemborongan (aannemer).

Orang/badan yang membiayai, merencanakan dan melaksanakan proyek konstruksi disebut dengan pihak pemangku kepentingan atau unsur-unsur pelaksana proyek.Masing- masing unsur mempunyai tugas, kewajiban dan tanggung jawab serta wewenang sesuai posisinya masingmasing. Dalam melaksanakan kegiatan masing-masing pihak sesuai posisinya berinteraksi satu sama lain sesuai hubungan kerja yang telah ditentukan (Wulfram, 2009). Koordinasi dari berbagai pihak yang terlibat dalam perencanaan, pelaksanaan, pengawasan dan pengendalian proyek merupakan kunci keberhasilan proyek.

\section{METODOLOGI}

Dengan penelitian ini maka akan dapat dibangun suatu teori yang berfungsi untuk menjelaskan, meramalkan, dan mengontrol suatu gejala. Penelitian ini menganalisis Kegagalan Konstruksi dari Perspektif Socio - Engineering System. Untuk memberikan kepastian, data yang dimiliki berdistribusi normal atau tidak, maka digunakan uji statistik normalitas.Untuk itu perlu suatu pembuktian. uji statistik normalitas yang digunakan dalam penelitian ini adalah Chi-Square. Salah satu metode dalam penelitian adalah metode deskriptif kuantitatif, dimana suatu metode dalam meneliti status sekelompok manusia, suatu objek, suatu kondisi, suatu sytem pemikiran, ataupun kelas peristiwa pada masa sekarang tujuan utama dalam melakukan penelitian deskriptif ialah untuk menggambarkan situasi atau objek dalam fakta yang sebenarnya, secara sistematis dan karakteristik dari subjek dan objek tersebut diteliti secara akurat, tepat dan sesuai kejadian yang sebenarnya.

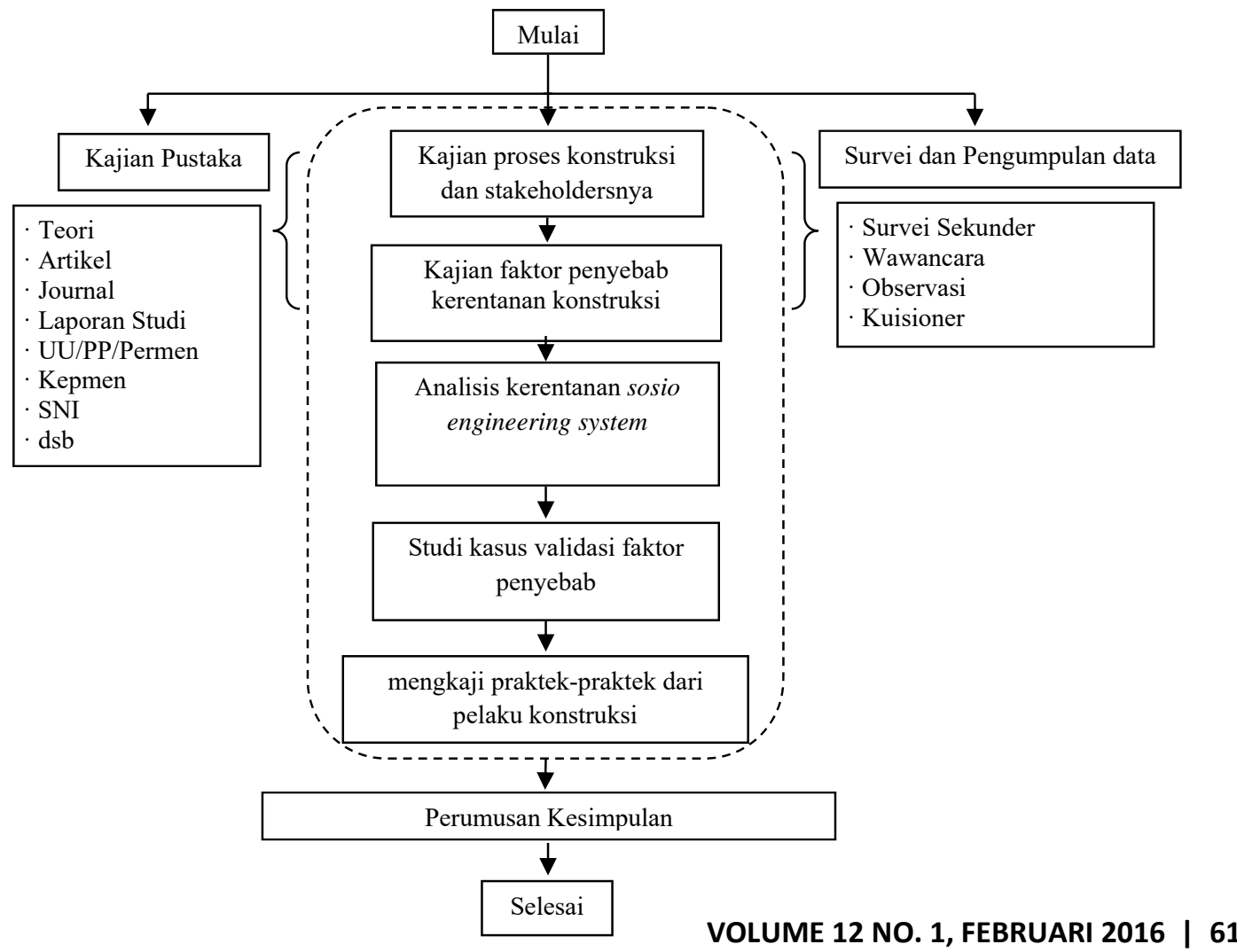


Gambar 3.1 Diagram Alir Metoda Penelitian

\section{HASIL PENELITIAN DAN PEMBAHASAN}

\subsection{Analisis Tingkat Kerentanan}

Dari data yang diteliti perlu dicermati mengenai fase tahapan - tahapan pada proyek yaitu Idea/Concept , Tahap Perencanaan Konstruksi ,Dokumen Perencanaan, Proses Pengadaan , Pelaksanaan Konstruksi, Evaluasi Produk/ Pemanfaatan Produk, Operasi dan Pemeliharaan . Dari tahapan-tahapan tersebut dinilai banyak terkandung faktor-foktor penyebab kerentanan bangunan dilihat dari perspektif sosio engineering system.

Tabel 4.1. Penilaian Kegagalan Konstruksi dan bangunan dari perspektif socio - engineering system

\begin{tabular}{lcc}
\hline Penilaian & Frekuensi & Persentase \\
& & 66,7 \\
Resiko & 20 & 33,3 \\
Tidak Beresiko & 10 & $\mathbf{1 0 0 , 0}$ \\
Total & $\mathbf{3 0}$ & \\
\hline
\end{tabular}

Data di atas menunjukkan bahwa dari 30 responden, 20 ( 66,7 \% ) responden menyatakan kegagalan konstruksi dari perspektif socio - engineering system termasuk kategori beresiko terhadap kegagalan konstruksi. Ini dapat diartikan prilaku / socio - engineering system menyumbang kontribusi yang negative terhadap dunia konstruksi dan perilaku manusia / pihak pihak yang berperan memiliki peranan yang cukup berarti dalam kegagalan bangunan.

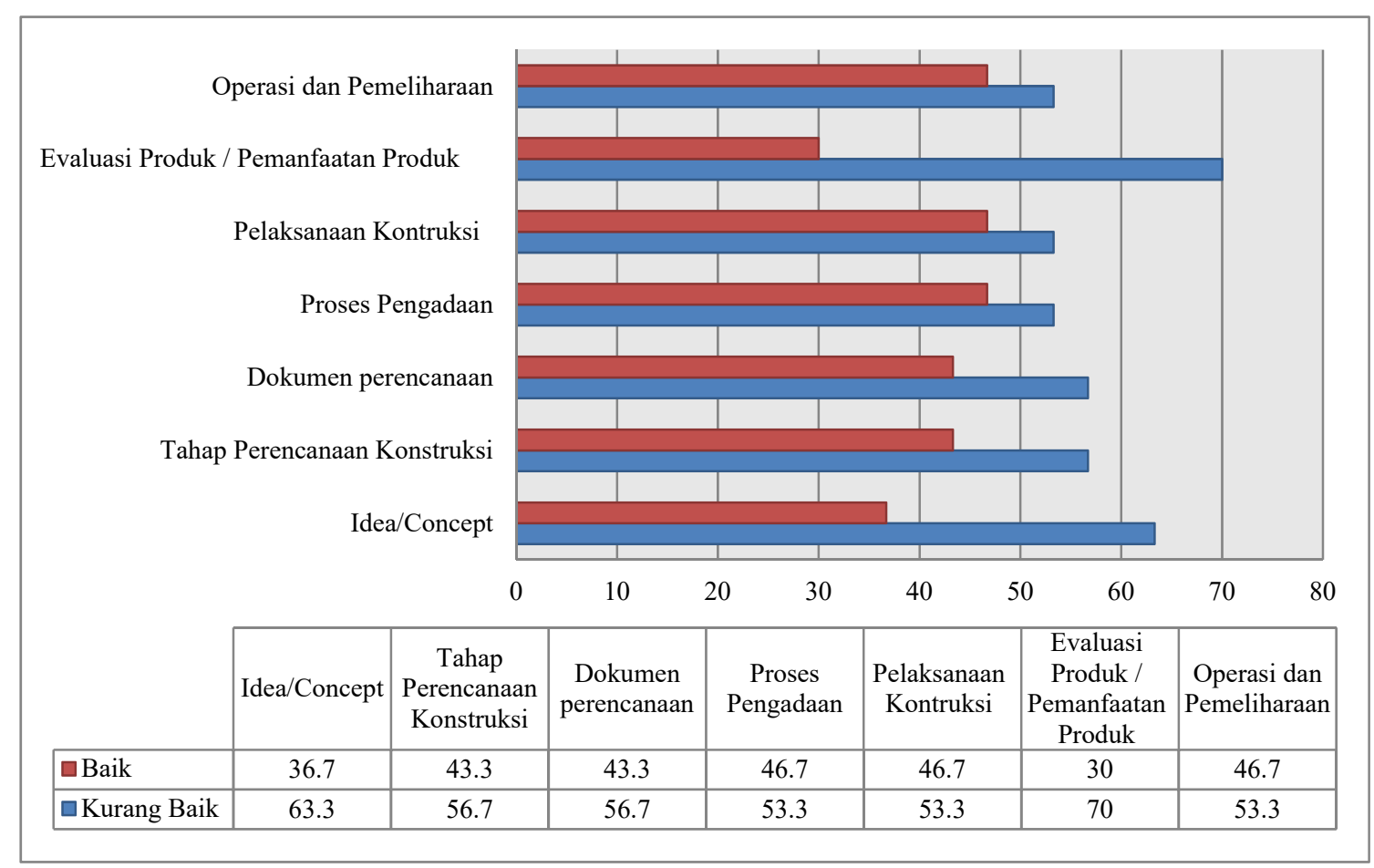


Gambar 4.1 Grafik persentase penyebab kerentanan bangunan dari sub fase Idea/Concept, Tahap Perencanaan Konstruksi ,Dokumen Perencanaan, Proses Pengadaan , Pelaksanaan Konstruksi, Evaluasi Produk/ Pemanfaatan Produk, Operasi dan Pemeliharaan

\subsection{Model Kuantitatif Kegagalan Konstruksi}

Analisis Korelasi Variabel Kuantitatif Model Kegagalan Konstruksi digunakan untuk menguji seberapa kuat hubungan tujuh variabel kuantitatif. Hasil Uji korelasi selengkapnya seperti disajikan pada Tabel berikut.

Tabel 4.1. Hubungan Sub Fase Idea/Concept Di Lihat Dari Perspektif Socio Engineering System Terhadap Kegagalan Kontruksi Dan Bangunan

\begin{tabular}{|c|c|c|c|c|c|c|c|c|}
\hline Idea/Concept & \multicolumn{3}{|c|}{ Kegagalan Kontruksi Dan Bangunan } & \multicolumn{2}{c|}{ Jumlah } & OR 95 \% CI & P-Value \\
& \multicolumn{2}{|c|}{ Beresiko } & \multicolumn{2}{c|}{ Tidak Beresiko } & & & & \\
\hline & Jml & $\%$ & Jml & $\%$ & Jml & $\%$ & & \\
\hline Kurang Baik & 13 & 65 & 6 & 60 & 19 & 63,3 & 1,238 & $\mathbf{0 . 7 8 9}$ \\
\hline Baik & 7 & 35 & 4 & 40 & 11 & 36,7 & & \\
\hline \hline Total & 20 & 100 & 10 & 100 & 30 & 100 & & \\
\hline
\end{tabular}

Tabel 4.2. Hubungan Sub Fase Tahap Perencanaan Konstruksi dari Perspektif Socio Engineering System Terhadap Kegagalan Kontruksi Dan Bangunan

\begin{tabular}{|c|c|c|c|c|c|c|c|c|}
\hline \multirow[t]{3}{*}{$\begin{array}{c}\text { Tahap Perencanaan } \\
\text { Konstruksi }\end{array}$} & \multicolumn{4}{|c|}{$\begin{array}{c}\text { Kegagalan Kontruksi Dan } \\
\text { Bangunan }\end{array}$} & \multicolumn{2}{|c|}{ Jumlah } & \multirow[t]{3}{*}{$\begin{array}{c}\text { OR } 95 \% \\
\text { CI }\end{array}$} & \multirow[t]{3}{*}{$\begin{array}{c}\text { P- } \\
\text { Value }\end{array}$} \\
\hline & \multicolumn{2}{|c|}{ Berisiko } & \multicolumn{2}{|c|}{ Tdk Berisiko } & & & & \\
\hline & $\mathbf{J m l}$ & $\%$ & $\mathbf{J m l}$ & $\%$ & $\mathbf{J m l}$ & $\%$ & & \\
\hline Kurang Baik & 14 & 70 & 3 & 30 & 17 & 56,7 & 5.444 & $\underline{0,037}$ \\
\hline Baik & 6 & 30 & 7 & 70 & 13 & 43,3 & & \\
\hline Total & 20 & 100 & 10 & 100 & 30 & 100 & & \\
\hline
\end{tabular}

Tabel 4.3. Hubungan Sub fase dokumen perencanaan dari Perspektif socio engineering system terhadap kegagalan kontruksi dan bangunan

\begin{tabular}{|c|c|c|c|c|c|c|c|c|}
\hline $\begin{array}{c}\text { Dokumen } \\
\text { Perecanaan }\end{array}$ & \multicolumn{3}{|c|}{$\begin{array}{c}\text { Kegagalan Kontruksi Dan } \\
\text { Bangunan }\end{array}$} & \multicolumn{2}{c|}{ Jumlah } & \multicolumn{2}{c|}{$\begin{array}{c}\text { O5 \% } \\
\text { CI }\end{array}$} & P-Value \\
\hline & \multicolumn{2}{|c|}{ Berisiko } & Tdk Berisiko & & & & \\
\hline & Jml & \% & Jml & \% & Jml & \% & & \\
\hline Kurang Baik & 14 & 70 & 3 & 30 & 17 & 56,7 & 5,444 & $\mathbf{0 , 0 3 7}$ \\
\hline \hline Baik & 6 & 30 & 7 & 70 & 13 & 43,3 & & \\
\hline Total & 20 & 100 & 10 & 100 & 30 & 100 & & \\
\hline
\end{tabular}

Tabel 4.4. Hubungan Sub fase Proses Pengadaan dari kerentanan socio engineering system terhadap kegagalan kontruksi dan bangunan

\begin{tabular}{|l|c|c|l|l|l|l|}
\hline Proses Pengadaan & \multicolumn{2}{|c|}{$\begin{array}{c}\text { Kegagalan Kontruksi Dan } \\
\text { Bangunan }\end{array}$} & Jumlah & OR 95\% CI & P-Value \\
& Berisiko & Tdk Berisiko & & & & \\
\hline & & & & & \\
\hline
\end{tabular}




\begin{tabular}{|c|c|c|c|c|c|c|c|c|}
\hline & Jml & $\mathbf{\%}$ & $\mathbf{J m l}$ & $\mathbf{\%}$ & $\mathbf{J m l}$ & $\mathbf{\%}$ & & \\
\hline Kurang Baik & 14 & 70 & 2 & 20 & 16 & 53,3 & 9,333 & $\underline{\mathbf{0 , 0 1 0}}$ \\
\hline Baik & 6 & 30 & 8 & 80 & 14 & 46,7 & & \\
\hline \hline Total & 20 & 100 & 10 & 100 & 30 & 100 & & \\
\hline
\end{tabular}

Tabel 4.5. Hubungan Sub fase Pelaksanaan Kontruksi dari Perspektif socio engineering system terhadap kegagalan kontruksi dan bangunan

\begin{tabular}{|c|c|c|c|c|c|c|c|c|}
\hline \multirow[t]{3}{*}{$\begin{array}{l}\text { Pelaksanaan } \\
\text { Kontruksi }\end{array}$} & \multicolumn{4}{|c|}{$\begin{array}{c}\text { Kegagalan Kontruksi Dan } \\
\text { Bangunan }\end{array}$} & \multicolumn{2}{|c|}{ Jumlah } & \multirow[t]{3}{*}{ OR $95 \%$ CI } & \multirow[t]{3}{*}{ P-Value } \\
\hline & \multicolumn{2}{|c|}{ Berisiko } & \multicolumn{2}{|c|}{ Tdk Berisiko } & & & & \\
\hline & Jml & $\%$ & $\mathbf{J m l}$ & $\%$ & $\mathbf{J m l}$ & $\%$ & & \\
\hline Kurang Baik & 13 & 65 & 3 & 30 & 16 & 53,3 & 4,333 & 0,070 \\
\hline Baik & 7 & 35 & 7 & 70 & 14 & 46,7 & & \\
\hline Total & 20 & 100 & 10 & 100 & 30 & 100 & & \\
\hline
\end{tabular}

Tabel 4.6. Hubungan Sub fase Evaluasi Produk / Pemanfaatan Produk dari Perspektif socio engineering system terhadap kegagalan kontruksi dan bangunan

\begin{tabular}{|c|c|c|c|c|c|c|c|c|}
\hline \multirow{3}{*}{$\begin{array}{c}\text { Evaluasi Produk / } \\
\text { Pemanfaatan } \\
\text { Produk }\end{array}$} & \multicolumn{4}{|c|}{$\begin{array}{c}\text { Kegagalan Kontruksi Dan } \\
\text { Bangunan }\end{array}$} & \multicolumn{2}{|c|}{ Jumlah } & \multirow[t]{3}{*}{ OR $95 \%$ CI } & \multirow[t]{3}{*}{ P-Value } \\
\hline & \multicolumn{2}{|c|}{ Berisiko } & \multicolumn{2}{|c|}{ Tdk Berisiko } & & & & \\
\hline & Jml & $\%$ & Jml & $\%$ & $\mathbf{J m l}$ & $\%$ & & \\
\hline Kurang Baik & 14 & 70 & 7 & 70 & 21 & 70 & 1,000 & 1,000 \\
\hline Baik & 6 & 30 & 3 & 30 & 9 & 30 & & \\
\hline Total & 20 & 100 & 10 & 100 & 30 & 100 & & \\
\hline
\end{tabular}

Tabel 4.7. Hubungan Sub fase Operasi dan Pemeliharaan dari Perspektif socio engineering system terhadap kegagalan kontruksi dan bangunan

\begin{tabular}{|l|c|c|c|c|c|c|c|c|}
\hline $\begin{array}{c}\text { Operasi dan } \\
\text { Pemeliharaan }\end{array}$ & \multicolumn{9}{|c|}{$\begin{array}{c}\text { Kegagalan Kontruksi Dan } \\
\text { Bangunan }\end{array}$} & \multicolumn{2}{c|}{ Jumlah } & OR 95 \% CI & P-Value \\
\hline & \multicolumn{7}{|c|}{ Berisiko } & \multicolumn{2}{|c|}{ Tdk Berisiko } & & & & \\
\hline & Jml & $\%$ & Jml & \% & Jml & \% & & \\
\hline Kurang Baik & 13 & 65 & 3 & 30 & 16 & 53,3 & 4,333 & $\mathbf{0 , 0 7 0}$ \\
\hline Baik & 7 & 35 & 7 & 70 & 14 & 46,7 & & \\
\hline \hline Total & 20 & 100 & 10 & 100 & 30 & 100 & & \\
\hline
\end{tabular}

Dari tabel hasil uji korelasi diatas terdapat tiga variabel yaitu :

Hasil uji statistik pada Sub fase Perencanaan Konstruksi diperoleh nilai $\mathrm{p}=0,037$ ( $\mathrm{p}$-value $<0,05$ ). Karena nilai P-value 0,037 >0,05, maka dapat disimpulkan ada hubungan yang bermakna antara tahap perencanaan dengan kegagalan kontruksi dan bangunan dan nilai $\mathrm{OR}=5,444$ artinya pada Tahap Perencanaan Konstruksi dengan beberapa sumber penyebab kerentanan dari sikap/ prilaku yang kurang baik sebesar 5,4 kali beresiko terhadap kegagalan kontruksi dan bangunan jika dibandingkan dengan sikap/ prilaku dari tahap perencanaan konstruksi yang baik.

Pada Sub fase Perencanaan Konstruksi faktanya tidak bisa dipungkiri fee atau komisi juga jual beli proyek setiap pekerjaan yang ada di pemerintah harus menggunakan fee atau komisi. Baik 64 I JURNAL REKAYASA SIPIL 
anggaran APBN maupun anggaran APBD semua sama. Besarnya fee atau komisi dalam setiap Proyek berbervariasi tergantung dari besarnya anggaran. Mulai dari 5\% sampai dengan 20\% bahkan ada yang lebih dari $40 \%$. Kalau tidak mengikuti ataran ini tentu tidak akan mendapatkan pekerjaan. Didasari atau tidak, pengguna jasa telah mengambil resiko. Pengguna jasa turut memegang saham dalam kumulasi resiko.

Hasil uji statistik pada Sub fase dokumen perencanaan diperoleh nilai $\mathrm{p}=0,037$ ( $\mathrm{p}$-value $<0,05$ ). Dengan demikian dapat disimpulkan ada hubungan yang bermakna antara dokumen perecanaan dengan kegagalan kontruksi dan bangunan dan nilai $\mathrm{OR}=5,444$ artinya dokumen perecanaan yang kurang baik sebesar 5,4 kali berisiko terhadap kegagalan kontruksi dan bangunan yang berisiko jika dibandingkan dengan dokumen perecanaan baik.

Pada Sub fase dokumen perencanaan faktanya dapat dilihat kerentanan socio-engineering system terhadap kegagalan bangunan yang timbul dari dokumen perencanaan seperti "Konsultan Perencana men sub kontrakan pekerjaan Perencanaannya kepada pekerja yang tidak profesional" sebesar $73,30 \%$. Keadaan ini diperburuk oleh kepincangan pengaturan hubungan primary consultant dan secondary consultant, ketidakseimbangan antara pembagian resiko dan imbalan, antara hak dan tanggung jawab. Maka diperlukan kebijaksanaan segi profesionalisme konsultan. Pada prakteknya main consultant mengadakan kerja sama kepada profesionalisme semu yang penuh gamling dengan tujuan dapat menekan imbalan jasa

Hasil uji statistik pada Sub fase Proses Pengadaan diperoleh nilai $\mathrm{p}=0,010$ ( $\mathrm{p}$-value $<0,05$ ). Dengan demikian hal ini dapat diartikan ada hubungan yang bermakna antara proses pengadaan dengan kegagalan kontruksi dan bangunan dan nilai $\mathrm{OR}=9,333$ artinya pada sub fase proses pengadaan dengan beberapa sumber penyebab kerentanan dari sikap/ prilaku yang kurang baik sebesar 9,3 kali beresiko terhadap kegagalan kontruksi dan bangunan jika dibandingkan dengan sikap/ prilaku dari proses pengadaan yang baik.

Pada Sub fase Proses Pengadaan hal ini dapat diartikan bahwa dalam sub fase pada proses pengadaan banyak terdapat indikasi - indikasi yang mengakibatkan kegagalan kontruksi dan bangunan. Banyak contoh kasus yang terjadi pada proyek konstruksi yang dapat memperkuat hasil dari analisa ini, salah satunya adalah persaingan yang tidak sehat ,korupsi, kolusi, nepotisme, (KKN) kecurangan dan penyuapan agar memenangkan tender Pengadaan Barang dan Jasa. Diantaranya dengan menggunakan cara - cara seperti mengondisikan peserta lelang " digugurkan" pada tahap evaluasi administrasi, membuat lelang dengan sistem arisan ( bergilir ), mengondisikan peserta lelang yang hanya diikuti oleh beberapa penyedia jasa saja serta indikasi lainnya dalam persekongkolan dalam proses pengadaan. Tentunya hal ini merupakan penyimpangan yang dikategorikan perbuatan melakukan praktik-praktik monopoli dan persaingan usaha yang tidak sehat yang nantinya akan menyebabkan kualitas pembangunan buruk, salah satunya dapat berdampak pada kerentanan bangunan sehingga memunculkan resiko korban. Selain itu juga berdampak terhadap ekonomi, lingkungan, kesehatan dan keselamatan manusia, dampak pada inovasi, erosi budaya, menurunnya tingkat kepercayaan kepada pemerintah, kerugian bagi perusahaan yang jujur, serta ancaman serius bagi pekembangan ekonomi.

\section{KESIMPULAN}

Berdasarkan hasil penelitian yang telah dilakukan, maka dapat diambil beberapa kesimpulan sebagai berikut:

- Kerentanan dari socio engineering system sangat berpengaruh terhadap kegagalan kontruksi dan bangunan sangat beresiko sebesar ( 66,7 \%) dalam arti kata perilaku 
manusia / pihak - pihak yang berperan memiliki peranan yang cukup berarti dalam kegagalan konstruksi dan bangunan.

- Kegagalan konstruksi dilihat dari persfektif socio engineering system tahapan yang berpengaruh yaitu pada tahap perencanaan, dokumen perencanaan dan proses pengadaan. Sumber penyebab kegagalan kontruksi dari perspektif Socio - Engineering System dinilai yang sangat beresiko yakni persaingan yang tidak sehat ,korupsi, kolusi, nepotisme, $(\mathrm{KKN})$ dan penyuapan agar memenangkan tender Pengadaan Barang dan Jasa dinilai ( 90,00\% ), Terjadinya persekongkolan dengan Owner untuk mengatur harga penawaran diluar prosedur pengadaan $(80,00 \%)$, Keinginan Owner untuk meraih keuntungan yang tidak normal ( Fee Proyek ) dengan menekan imbalan jasa dari konsultan Perencana / Kontraktor diluar kontrak yang telah disepakati $(76,7 \%)$

\section{DAFTAR KEPUSTAKAAN}

Carper, Kenneth L. ed.1989. Forensic Engineering. Elsevier Science Publishers. New York.

Cartlide dan Mehrtens. 1982. Practical Cost Planning A Guide for surveyors and architects. Hutchinson \& Co (Publisher) Ltd. London.

Chapman,C. 1997. Project Risk Analysis and Management - PRAM the Generic

Cooper, D. dan Chapman, C. 1993. Risk Analysis For Large Project. First Edition.

Cooper, D. Grey, S. Raymond,G. dan Walker,P. 2005. Project Risk Management

Djojosoedarso, Soeisno. 2003. Prinsip-prinsip Manajemen Resiko Asuransi. Edisi Pertama.

Ervianto, Wulfram. 2009. Manajemen Proyek Konstruksi. Andi. Yogyakarta.

Gray,C.F dan Larson,E.W. 2000. Project Management. First Edition. Irwin Mc Graw-Hill, Boston.

Guidelines. John Wiley \& Sons Ltd., England.

Guilford,J.P., B. Fruchter (1981), Fundamental Statistics In Psychology And Education, Tokyo: McGrawHillKogakusha, Ltd.

Hartanto, Agnes Olivia (2006) Model pengaruh faktor laten terhadap perilaku pekerja pada cacat konstruksi. Master thesis, Petra Christian University

John Wiley \& Sons, Ltd. 2008, The Atrium, Southern Gate, Chichester, PO19 8SQ, England ("Wiley")

Kerlinger, F. N dan Lee, H. B .2000. Foundation of Behavioral Research (Fourth Edition), USA ; Holt, Reinnar \& Winston. Inc

Kerzner Harold, 2001. Project Management: A System to Planning, Scheduling and Controlling, (7 th Edition, John Wiley \& Sons), hal. 3.

Oyfer. 2002. Multiple Sources Construction Failures and Defects

PMI ( Project Managemen Institute, Inc ). 2004 . A Guide To The Project Managemen Body Of Knowledge ( PMBOK), 3 rd edition, Newtown Square, Pennsylvania, USA.

Pranoto. 1997. Faktor kegagalan konstruksi. dalam Kurniawan, Y.T., 2012. Simulasi 1-D Banjir Akibat Keruntuhan Bendungan Alam (Studi Kasus Bencana Banjir Bandang di Sungai Kaliputih Kabupaten Jember tahun 2006). Thesis. Yogyakarta: Universitas Gadjah Mada

Process . International Journal of Project Magement, Vol.15. No. 5.

Ramli, Samsul. 2013. Bacaan Wajib Para Praktisi Pengadaan Barang/Jasa Pemerintah. Jakarta : Visimedia.

Republik Indonesia. 1999. Undang - undang Nomor 18 Tahun 1999 tentang Jasa Konstruksi. Sekretariat Negara. Jakarta.

Republik Indonesia. 1999. Undang - undang Nomor 5 Tahun 1999 tentang Larangan Praktek Monopoli dan Persaingan Usaha Tidak Sehat. Sekretariat Negara. Jakarta

Republik Indonesia. 1999. Undang - undang Tindak Pidana Korupsi Nomor 31 Tahun 1999 tentang Pemberantasan Tindak Pidana Korupsi.Sekretariat Negara. Jakarta.

Republik Indonesia. 1999. Undang-undang Nomor 32 Tahun 2009 tentang Perlindungan Lingkungan Hidup, dan Pelaksanaannya. Sekretariat Negara. Jakarta.

Republik Indonesia. 2004. Undang-undang Nomor 1 Tahun 2004 tentang perbendaharaan negara. Sekretariat Negara. Jakarta.

Republik Indonesia. 2010. Peraturan Presiden Nomor 54 Tahun 2010 tentang Pengadaan Barang / Jasa Pemerintah. Sekretariat Kabinet RI. Jakarta. 
Republik Indonesia. 2011. Peraturan Presiden Nomor 35 Tahun 2011 tentang Perubahan atas Peraturan Presiden Nomor 54 Tahun 2010 tentang Pengadaan Barang/Jasa Pemerintah. Sekretariat Kabinet RI. Jakarta.

Republik Indonesia. 2012. Peraturan Pemerintah Nomor 27 Tahun 2012 tentang Izin Lingkungan.

Republik Indonesia. 2013. Keppres No. 80/2003 Tentang Pedoman Pelaksanaan Pengadaan Barang/Jasa Pemerintah. Sekretariat Kabinet RI. Jakarta.

Shahab, Hamid. 1996, Langkah Memperkecil Risiko Dalam Pembangunan, Cetakan Pertama, Penerbit Djambatan, Jakarta.

Soeharto. 1999.Manajemen Proyek 1. Erlangga. Jakarta. Soeharto. 2001. Manajemen Proyek 2.Erlangga. Jakarta.

Sunarti, E. 2009. Analisis Kerentanan Sosial Ekonomi Penduduk dan Wilayah untuk Analisis Resiko Bencana. Makalah disampaikan sebagai bahan Penyusunan Rencana Nasional Penanggulangan Bencana Indonesia 2009-2013.

Susanto Hendra \& Makmur Hediana. 2013. Auditing Proyek-proyek Konstruksi. Yogyakarta: Andi Offset. Suswinarno. 2013. Mengantisipasi Risiko dalam Pengadaan Barang/Jasa Pemerintah. Jakarta: Visimedia

Suwandi. 2010. Kajian Manajemen Resiko pada Proyek dengan Sistem Kontrak Lump Sum dan Sistem Kontrak Unit Proce (Studi Kasus : Proyek Jalan dan Jembatan, Gedung, Bangunan Air). Tesis Program Pascasarjana Magister Teknik Sipil Universitas Diponegoro. Semarang.

Tumilar. 2006. Latar belakang dan Kriteria dalam Menentukan Tolok Ukur Kegagalan Bangunan.HAKI.Jakarta.

Vickynasyon, 2002, Total Project Risk in Construction. New York. 